Mini Review

\title{
Electroanalytical Methods for Fish Drug Determination and Control: A Review and Outlook
}

\author{
Li Fu ${ }^{1,2^{*}}$, Yuting $X u^{1}$, Jia Du ${ }^{1}$, Di Cao ${ }^{3}$ and Qinghua $\mathrm{Liu}^{2^{*}}$ \\ ${ }^{1}$ College of Materials and Environmental Engineering, Hangzhou Dianzi University, Hangzhou \\ 310018, PR China \\ ${ }^{2}$ Hongze Fishseeds Biotech, Inc. Hongze, Huaian, 223125, PR China \\ ${ }^{3}$ Suzhou Eco-man Biotechnology, Inc. Suzhou, 215141, PR China \\ *E-mail: fuli@hdu.edu.cn, 1103795946@qq.com
}

doi: 1020964/2019.05.32

Received: 5 January 2019 / Accepted: 13 February 2019 / Published: 10 April 2019

Fishery drugs can kill pathogens of aquatic animals and increase the production of aquatic products. These compounds have been widely used in the past 30 years. However, in recent years, abuse and misuse of these drugs has caused great economic losses and serious consequences and has endangered human health. Accelerating the establishment of aquatic product quality inspection systems is an effective way to guarantee the quality and safety of aquatic products and public health and safety. The most important aspect is to speed up the improvement of aquatic product quality in addition to safety inspection and detection capabilities. In this review, we describe the recent development of electrochemical sensors for fishery drug detection and determination. This paper provides a reference for the aquaculture industry and academic research for selecting the most suitable detection technology for different fishery drugs.

Keywords: Fishery drug determination; Electrochemical sensor; Review; Electrode modification; Analytical determination

\section{$\underline{\text { FULL TEXT }}$}

(C) 2019 The Authors. Published by ESG (www.electrochemsci.org). This article is an open access article distributed under the terms and conditions of the Creative Commons Attribution license (http://creativecommons.org/licenses/by/4.0/). 